\title{
Effect of Doping at TiO2-Nanotubular Gas Sensors
}

\author{
Gönüllü, Yakup/ Mondragón-Rodríguez, C.G/ Saruhan-Brings, Bilge/ \\ German Aerospace Center (DLR) \\ Linder Höhe \\ 51147 Cologne, Germany
}

Bayata, Fatma/ Ürgen Mustafa

Istanbul Technical University (ITU)

34469 Maslak, Istanbul, Turkey

\section{Introduction}

In the last decades, atmospheric pollution in urban areas has achieved to critical levels. Processes involving combustion in aircrafts, energy and power production and automobile engines as well as through industrial settlement are the main sources of the pollution. Detection and control of the emission relies on the development of the precious and selective gas sensors [1]. It is known that the transition metal oxides such as $\mathrm{SnO}_{2}, \mathrm{TiO}_{2}, \mathrm{WO}_{3}, \mathrm{MoO}_{3}, \mathrm{Ga}_{2} \mathrm{O}_{3}$ and $\mathrm{Nb}_{2} \mathrm{O}_{5}$ are used as sensing electrodes in such chemical gas sensors due to their semiconducting and electrochemical properties [2]. $\mathrm{TiO}_{2}$ is non-toxic and low cost and has excellent chemical stability. It can pose semi-conductive properties on doping, and hence is one of the most important transition metal oxides for this purpose [3, 4]. Nevertheless, $\mathrm{TiO}_{2}$ based gas sensors still need improvement for the achievement of high-temperature sensitivity, stability or efficiency. One of the methods to improve the performance of the $\mathrm{TiO}_{2}$-based gas sensor devices is the increase of surface area by structuring the sensors. An electrochemical reaction occurs, as a gas species, either oxidizing or reducing, reaches on the semi-conductive metal oxide surface. Thus, the quantity of this reaction relies on the availability of the surface area of the metal oxide. Second solution for higher efficiency or sensitivity and better selectivity at the $\mathrm{TiO}_{2}$-based gas sensor devices is the doping of $\mathrm{TiO}_{2}$ with different valence elements such as $\mathrm{Cr}^{3+}, \mathrm{Al}^{3+}, \mathrm{Nb}^{5+}, \mathrm{W}^{6+}$, etc. It is known that doping of $\mathrm{TiO}_{2}$ with $\mathrm{Cr}^{3+}$ causes a change in semi-conductivity, leading to improvement in $\mathrm{NO}_{2}$-gas sensitivity of $\mathrm{TiO}_{2}$-based gas sensors [5].

In this study, we report the synthesis of highly ordered $\mathrm{Cr}$ - or $\mathrm{Al}$-doped $\mathrm{TiO}_{2}$ nano-tubes by anodic oxidation. The sensors produced using these nano-tubular layers are investigated for the sensing properties towards $\mathrm{NO}_{2}$ and $\mathrm{CO}$ at the temperature range of $300^{\circ} \mathrm{C}-500^{\circ} \mathrm{C}$.

\section{Experimental Process}

Highly-ordered pure $\mathrm{TiO}_{2}$ nano-tubes were grown on the commercially available pure titanium foil (99.6\%) via anodic oxidation. First the titanium foil substrates were mirror polished and then rinsed with the deionized water. Following every polishing step, the foils are cleaned in an ultrasonic bath. The anodization process was carried out in two different solutions; (1) Ethylene Glycol (EG) - based electrolyte containing $2 \%$ vol. $\mathrm{H}_{2} \mathrm{O}, 98 \%$ voland $0.3 \%$ wt. $\mathrm{NH}_{4} \mathrm{~F},(2)$ aqueous electrolyte containing $0.5 \mathrm{M} \mathrm{H}_{3} \mathrm{PO}_{4}$ and $0.14 \mathrm{M} \mathrm{NaF}$ using an anodization voltage of $20 \mathrm{~V}$.

Before the sensor measurements, all samples were annealed at $450^{\circ} \mathrm{C}$. The sensor characterization measurements were carried out under $\mathrm{NO}_{2}$ or $\mathrm{CO}$ after depositing two platinum circuits on the Nanotubular-layers at test temperature of $300^{\circ} \mathrm{C}$. A constant voltage of $60 \mathrm{~V}$ was applied and the resistance changes of the sensor devices were recorded upon exposure to $\mathrm{NO}_{2}$-in the concentrations of $10 \mathrm{ppm}$ to $25 \mathrm{ppm}$.

\section{Results and discussion}

Well-ordered $\mathrm{TiO}_{2}$ and the metal-doped $\mathrm{TiO}_{2}$ nano-tubular layers could be obtained after anodization process. The surface and cross-section images of the $\mathrm{TiO}_{2}$ layer achieved after 1 hour anodic oxidation are shown in Figs. 1a and 1b. In one hour of anodization, nano-tubes lengths of 4-6 $\mu \mathrm{m}$ were achieved. After three hours, the thickness can reach to $16 \mu \mathrm{m}$. Figs. 1c and 1d show top view and cross-section images of $\mathrm{Cr}^{3+}$-doped $\mathrm{TiO}_{2}$ nano-tubular layer. 

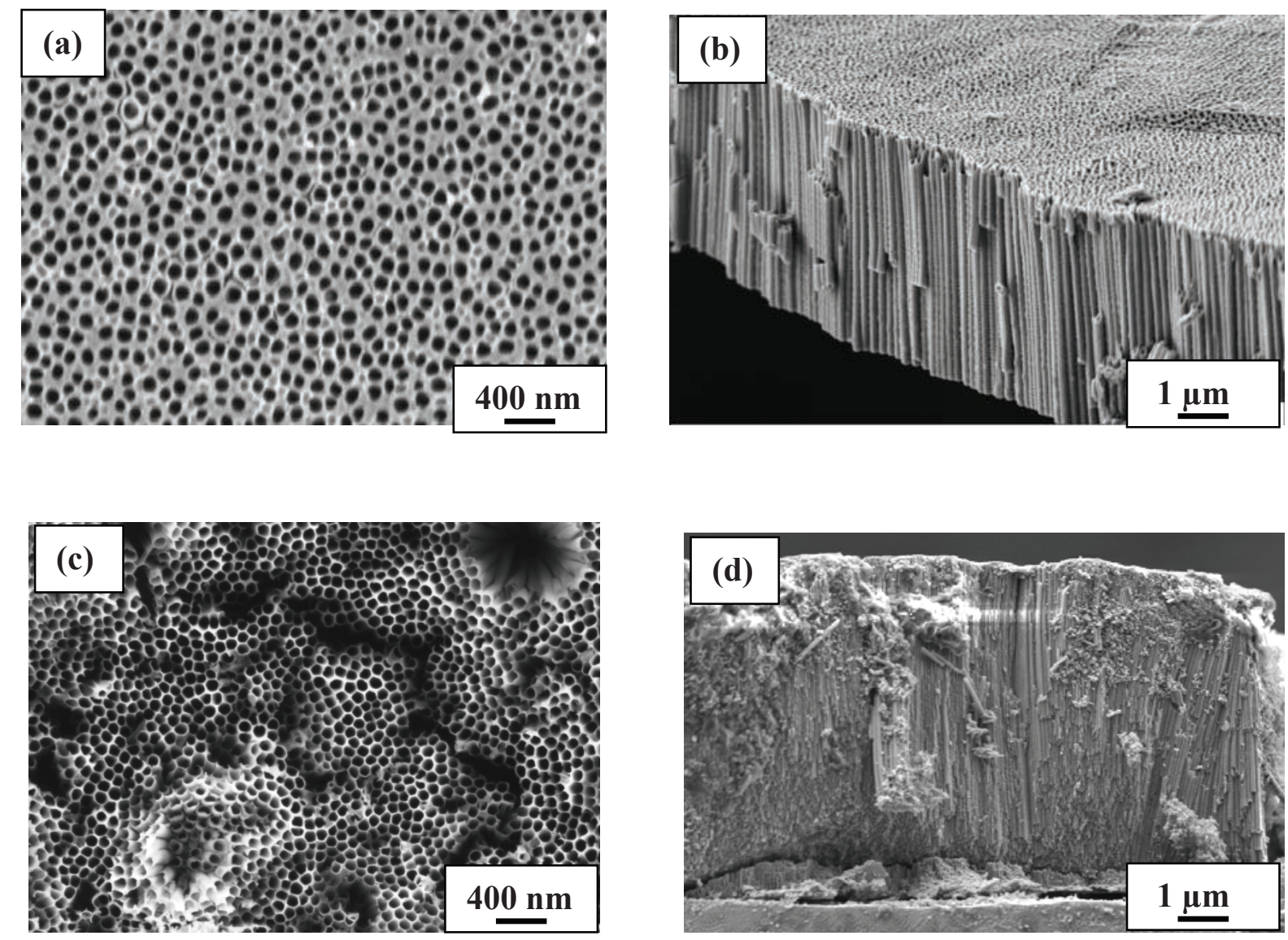

Fig. 1: SEM images of $\mathrm{TiO}_{2}$ nano-tubular layer after anodic-oxidation at $60 \mathrm{~V}$ using EG-based electrolyte (a) top view (b) cross-section of undoped $\mathrm{TiO}_{2}$, (c) top view and (d) cross section of $\mathrm{Cr}^{3+}$ doped $\mathrm{TiO}_{2}$

Fig. $2 \mathrm{a}$ shows the sensor response of the undoped $\mathrm{TiO}_{2^{-}}$nano-tubular layers under $\mathrm{NO}_{2}$ concentrations of 10,15 and $20 \mathrm{ppm}$ at $300^{\circ} \mathrm{C}$. On release of the $10 \mathrm{ppm} \mathrm{NO}$, a sharp increase at resistance value was observed. When the $\mathrm{NO}_{2}$ flow is stopped, the resistance value decreased to the original level. However, under increased $\mathrm{NO}_{2}$ flow (e.g. 15 ppm), the increase at resistance can not reach to a steady state. On contrast, the response of the $\mathrm{Cr}$-doped nano-tubular $\mathrm{TiO}_{2}$-layers was very stable towards the same $\mathrm{NO}_{2}$-concentrations, yielding very short response times (Fig. $2 \mathrm{~b}$ ). Moreover, the resistivity change showed no drift with and without $\mathrm{NO}_{2}$ flow. The same baseline as well as sensor response were stable.
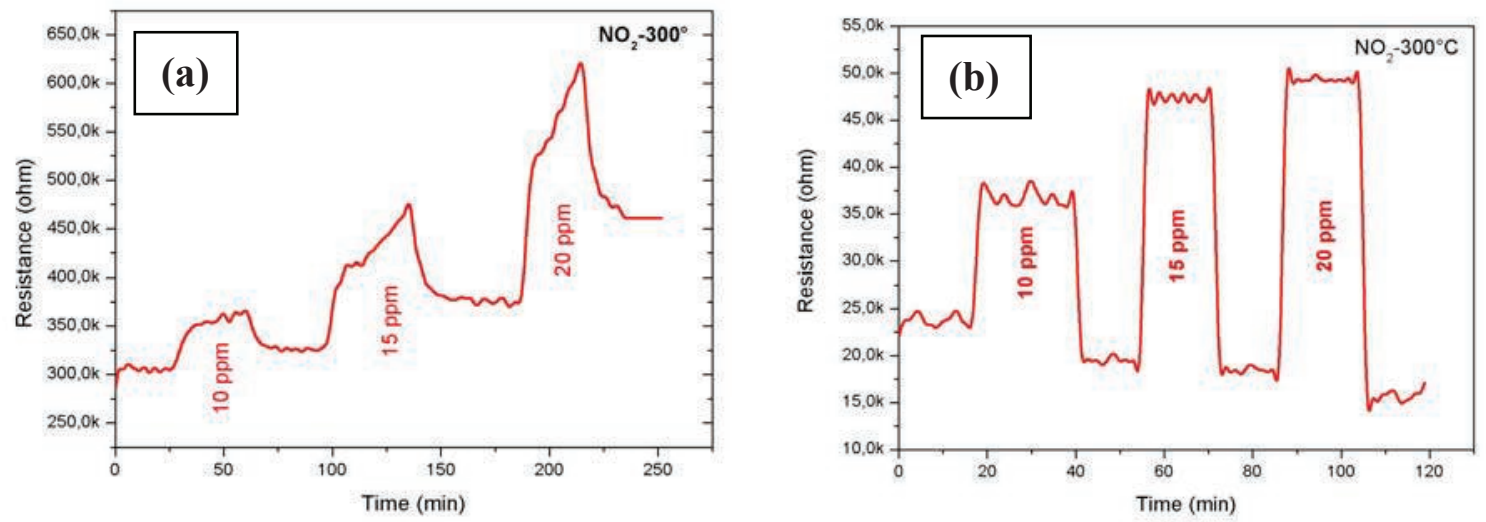

Fig. 2: Sensor response towards $\mathrm{NO}_{2}$ at $300^{\circ} \mathrm{C}$ (a) undoped $\mathrm{TiO}_{2}$ nano-tubular layer (b) $\mathrm{Cr}^{3+}$-doped $\mathrm{TiO}_{2}$ nano-tubular layer 


\section{Conclusion}

Vertically aligned $\mathrm{TiO}_{2}$ nano-tube arrays were synthesized in EG-based electrolytes. The sensor measurements were carried out at $300^{\circ} \mathrm{C}$ with $\mathrm{NO}_{2}$ concentrations of 10,15 and $20 \mathrm{ppm}$. The nanostructured $\mathrm{TiO}_{2}$-gas sensor showed reasonably well response towards $\mathrm{NO}_{2}$ but the resistivity change was not stable during the $\mathrm{NO}_{2}$ flow. On Cr-doping of the $\mathrm{TiO}_{2}$ nano-tubes, the gas sensing activity of the sensor towards $\mathrm{NO}_{2}$ was increased. The resistivity change was stable and fast with and without $\mathrm{NO}_{2}$ flow. Structuring and doping the $\mathrm{TiO}_{2}$ layers, and thus increasing the surface area, at the gas sensor electrodes, more sensitive and stable response can be obtained. The response and recovery times of the sensor can be reduced. $\mathrm{Cr}^{3+}$-doped $\mathrm{Nano}$-tubular $\mathrm{TiO}_{2}$-electrodes yield very promising sensor devices for stable and sensitive detection of relatively small concentrations of $\mathrm{NO}_{2}$.

\section{References}

[1] Y. Jun, H.S. Kim, J.H. Lee and S. H. Hong, CO Sensing performance in micro-arc oxidation $\mathrm{TiO}_{2}$ films for air quality, Sens. Actuators B, (2006), 69-73.

[2] A. M. Ruiz, G. Sakai, A. Cornet, K. Shimanoe, J. R. Morante and N. Yamazoe, Cr-doped $\mathrm{TiO}_{2}$ gas sensor for exhaust $\mathrm{NO}_{2}$ monitoring, Sens. Actuators $B$ (2003), 509-518.

[3] K. Zakrzewska, Mixed oxides as gas sensors, Thin Solid Films 391 (2001) 229-238.

[4]Y. Xu, K. Yao, X. Zhou, Q. Cao, Platinum-titania oxygen sensors and their sensing mechanisms, Sens. Actuators B: Chem. 13-14 (1993) 492-494.

[5] A.M. Ruiz, J. Arbiol, A. Cirera, A. Cornet, J.R. Morante, Surface activation by Pt-nanoclusters on titania for gas sensing applications, Mater. Sci. Eng. C 19 (2002) 105-109. 